\title{
Michelia Essential Oil Inhalation Increases Fast Alpha Wave Activity
}

\author{
Phanit Koomhin 1,2,3,*, Apsorn Sattayakhom 2,4, Supaya Chandharakool ${ }^{4}$, \\ Jennarong Sinlapasorn ${ }^{4}$, Sarunnat Suanjan ${ }^{4}$, Sarawoot Palipoch ${ }^{1}$, Prasit Na-ek ${ }^{1}$, \\ Chuchard Punsawad ${ }^{1}$ and Narumol Matan ${ }^{2,5}$ \\ 1 School of Medicine, Walailak University, Nakhonsithammarat 80160, Thailand; sarawoot.pa@wu.ac.th (S.P.); \\ prasit.na@wu.ac.th (P.N.-e.); chuchard.pu@wu.ac.th (C.P.) \\ 2 Center of Excellence in Innovation on Essential oil, Walailak University, \\ Nakhonsithammarat 80160, Thailand; apsorn.sa@wu.ac.th (A.S.); nnarumol6296@gmail.com (N.M.) \\ 3 Research Group in Applied, Computational and Theoretical Science (ACTS), Walailak University, \\ Nakhonsithammarat 80160, Thailand \\ 4 School of Allied Health Sciences, Walailak University, Nakhonsithammarat 80160, Thailand; \\ Supaya.ch@mail.wu.ac.th (S.C.); Drank.abc@gmail.com (J.S.); Sarunnat.suan@gmail.com (S.S.) \\ 5 School of Agricultural Technology, Walailak University, Nakhonsithammarat 80160, Thailand \\ * Correspondence: phanit.ko@mail.wu.ac.th; Tel.: +66-95295-0550
}

Received: 13 February 2020; Accepted: 6 May 2020; Published: 9 May 2020

\begin{abstract}
Essential oils are volatile fragrance liquids extracted from plants, and their compound annual growth rate is expected to expand to 8.6\% from 2019 to 2025, according to Grand View Research. Essential oils have several domains of application, such as in the food and beverage industry, in cosmetics, as well as for medicinal use. In this study, Michelia alba essential oil was extracted from leaves and was rich in linalool components as found in lavender and jasmine oil. The effects of inhaling michelia oil on human brainwaves still need to be elucidated. Ten male and ten female subjects were recruited. Thirty-two-channel electroencephalography was recorded. The raw data were spectrally analyzed for slow alpha, fast alpha, low beta, mid beta, and high beta activities. The results demonstrate that michelia leaf oil could reduce the alertness level observed by beta wave decrease and fast alpha wave activity increase. The inhalation of pure linalool showed virtually identical responses as the michelia oil inhalation. In conclusion, the sedative effects of michelia oil inhalation might originate from its major linalool component.
\end{abstract}

Keywords: michelia essential oil; linalool; electroencephalography; power spectral analysis

\section{Introduction}

Essential oils are volatiles extracted from plants which have been used for fragrance purposes for centuries. They have several psychophysiological effects on the human body and mind. The use of aromatherapy started to gain a lot of attention in the late 20th century and became very popular in the 21st century [1]. Essential oils are mostly used in the food and beverage industry, followed by spa, relaxation, and medicinal fields. Essential oils have several interesting biological properties, such as anticancer, antibacterial, antifungal, anti-inflammatory, and antioxidant activities [2-6]. For aromatherapy, essential oils are used as the main therapeutic agent. The mechanism of action of essential oils involves the interaction of essential oil molecules with odorant receptors at the cell membrane of olfactory sensory cells in the olfactory epithelium during inhalation. The signal will be then transmitted to several regions of the brain [7]. Another possible mechanism is the pharmacological actions of the odorant molecule itself as an agent absorbed into the blood circulation [8]. 
Michelia alba, or white champaka, belongs to the family Magnoliaceae. Michelia alba originates from southern Asia. It has acclimatized in many regions of the world and has been widely used in traditional ceremonies because of its quiescent smell. The essential oil from their flowers has useful applications in perfumery and in pharmaceutical industries. Essential oils can be extracted not only from their flowers but also from their leaves. There is no evidence that supports its essential oil effects in humans. The volatile oil from leaves of Michelia alba is composed of several components, mainly linalool, caryophyllene, 1,3,7-octatriene, germacrene-D, and humulene [9]. Linalool is the major component of several famous plants, such as lavender, jasmine, and cannabis. Linalool effectively decreases beta waves after work and increases positive moods [10,11]. Lavender, chamomile, sandalwood, and eugenol decrease alpha 1 or slow alpha activity at the parietal and posterior temporal region of the brain and increases theta and alpha activities, according to another study [12]. Jasmine increases beta waves in the anterior center and the left posterior regions [13]. Cannabis essential oil decreases beta waves and increases alpha wave activity [14]. Michelia alba essential oil has been reported to have antifungal, antimicrobial, and antioxidant activities [15-17]. However, there is no evidence on the effect of Michelia alba oil inhalation on human brainwaves, and this oil has a different combination of several components in nature. In this study, we investigated the effect of Michelia alba oil and pure linalool oil on moods, alpha, and beta wave activities.

\section{Materials and Methods}

\subsection{Essential Oils}

Michelia alba oil used in this study is an extract of Michelia alba leaves, supplied by the Thai China Flavor \& Fragrance Industry Co., Ltd. (Thailand). Their constituents were analyzed by Suhem et al. using gas chromatography-mass spectrometry (GC-MS). Briefly, GC-MS analyses were accomplished using a gas chromatograph (Hewlett Packard Model 7890A, California, USA) equipped with a DB-5 (J\&W Scientific, California, USA) column ( $30 \mathrm{~cm} \times 0.25 \mathrm{~mm}$ ID) and a coat film $(0.25 \mathrm{~mm}$. of thickness). The average helium carrier gas flow rate was 1 milliliter per minute, the split ratio of the column was 40: 1 , and the injector and detector were temperature programmed at $250{ }^{\circ} \mathrm{C}$ and $260^{\circ} \mathrm{C}$, respectively. The column oven temperature was set at $60^{\circ} \mathrm{C}$ for 30 seconds, increased to $150{ }^{\circ} \mathrm{C}$ with $40{ }^{\circ} \mathrm{C}$ per minute increasing rate and then to $260{ }^{\circ} \mathrm{C}$ at $2{ }^{\circ} \mathrm{C}$ per minute increasing rate. Identification of the constituents was based on comparison with authentic samples, comparison their Kovats retention indices and computer matching with the NIST $0.8 \mathrm{~L}$ (Database/ChemStation data system). According to these analyses, Michelia alba leaf oil consisted of the following compounds: linalool (73.74\%), caryophyllene $(7.35 \%), 1,3,7$-octatriene (3.41\%), germacrene-D (2.41\%), humulene (1.97\%), selinene (1.45\%), nerolidol $(1.06 \%)$, and copaene $(0.66 \%)$ of $92.05 \%$ in total [9]. Pure linalool (food grade) was purchased from Sigma Aldrich (Buchs, Switzerland.

\subsection{Subjects}

Ten male and 15 female healthy subjects were recruited in this study. The experimental protocol was approved by the Human Research Ethics Committee of Walailak University. The approval number is WUEC-16-043-01(14 June 2017). All subjects had adequate sleep (more than six hours) prior to the test day. Alcohol, smoking, and coffee were forbidden for a week before testing. A smell test was performed using ten odorant stimuli. A seven-point analysis of correct subjects was further accessed as the following experimental protocols. A motor task was also tested, which is why we only included right-handed persons in the tests.

\subsection{Experimental Protocols}

The protocol was adapted from Sowndhararajan et al. [18]. The subjects sat quietly in a recliner. Essential oil application was modified from other studies [7]. The subjects were instructed to open and close their eyes for three-minute intervals during the absence and presence of odorant stimuli. 
Fifty microliters of undiluted michelia oil were dropped on a filter paper. The filter paper with or without the essential oil was then attached to the subject's nose. Ten male and ten female subjects were presented with a michelia-oil-spotted filter paper and the other five female subjects were further preliminarily tested with pure linalool oil.

\subsection{Data Acquisition and Processing}

Electroencephalography (EEG) was measured using Compumedics Neuroscan with SynAmps RT 64-channel amplifier. The subjects wore a Quik cap on their heads and 32 channels were loaded with Quik gel to improve connectivity. FP1, FP2, AF3, AF4, F7, F3, FZ, F4, F8, FC5, FC1, FC2, FC6, T7, C3, CZ, C4, T8, CP5, CP1, CP2, CP6, P7, P3, PZ, P4, P8, PO7, PO3, OZ, PO4, PO8 electrodes were recorded with a sampling rate of $1 \mathrm{kHz}$. Electrode impedances were adjusted to be lower than $5 \mathrm{k} \Omega$. Raw data during eye-closed periods were then analyzed with a triplicate of a thirty-second epoch size. Raw data were processed, filtered, and artifact reduced using Curry 7 software (Compumedics). Three 10-second epochs were chosen to be analyzed per condition. Time domain data were then transformed to frequency domain data via fast Fourier transform. Power spectral analysis was finally performed to clearly display the differences among frequencies.

\subsection{Statistical Analyses}

The power values $\left(\mu \mathrm{V}^{2}\right)$ were compared during the absence and presence of odor stimuli among and between genders. All the statistical analyses and graphical figures were performed using the GraphPad Prism software. Kruskal-Wallis test was performed to analyze the difference among the groups, and Wilcoxon matched-pairs signed rank test was then used to compare the results between the groups. Statistical differences were then considered if the $p$-value was less than 0.05. Data are shown as mean \pm SEM.

\section{Results}

\subsection{Effects of Michelia Essential Oil and Linalool Component Inhalation on Brainwaves}

To exclude age and circadian variations, subjects that were almost identical were recruited, and all experiments were conducted in the same period (Table 1). Because of brain dominance, motor task was performed using the Stim2 software (Compumedics). A positive value of dominance scores implied that all volunteers were right-handed. The simple odor administration method provided odorant diffusion without olfactory adaptation, thus, the subjects could percept the oils throughout the testing interval. Raw EEG traces were analyzed to slow alpha $(9 \mathrm{~Hz})$, fast alpha $(12 \mathrm{~Hz})$, low beta $(14 \mathrm{~Hz})$, mid beta $(17 \mathrm{~Hz})$, and high beta frequencies $(25 \mathrm{~Hz})$. In female subjects, low beta activity was dominant at rest while slow alpha was the dominant resting wave frequency in male subjects (Figure 1). The michelia oil inhalation induced a shift in the brainwave in the female subjects from low beta dominance to fast alpha wave frequency dominance. However, the brainwave shift was not observed in the male subjects. In the female subjects, the oil inhalation decreased the powers of slow alpha wave activity while it increased fast alpha and high beta activities. The oil inhalation showed fewer effects in the male subjects, where it decreased slow alpha and high beta activities. The essential oil inhalation showed gender differences in brainwave responses, specifically at fast alpha, low beta, and high beta brainwaves. Overall, altered activities in both genders tended to be a more female response. The michelia oil used in this research was composed of linalool as the major component and because of less activity in male subjects. We further investigated 1:400 dilution of linalool inhalation in five more female subjects. The result showed identical responses in slow and fast alpha wave patterns (Figure 2). However, it also effectively decreased all beta wave groups. 
Table 1. Baseline characteristics of female and male subjects involved in the michelia oil inhalation experiment. Data shown as mean \pm SEM.

\begin{tabular}{ccccc}
\hline Gender & Numbers & Age & BMI & Dominance Score \\
\hline Male & 10 & $21.1 \pm 0.18$ & $22.73 \pm 1.23$ & $14.59 \pm 2.34$ \\
Female & 10 & $21.5 \pm 0.17$ & $21.77 \pm 0.98$ & $15.99 \pm 3.63$ \\
\hline
\end{tabular}

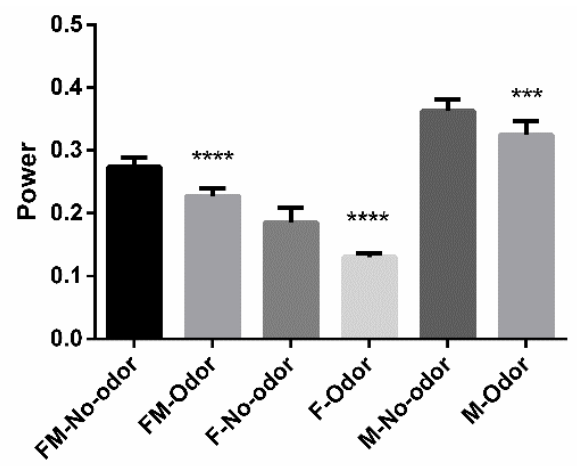

(a)

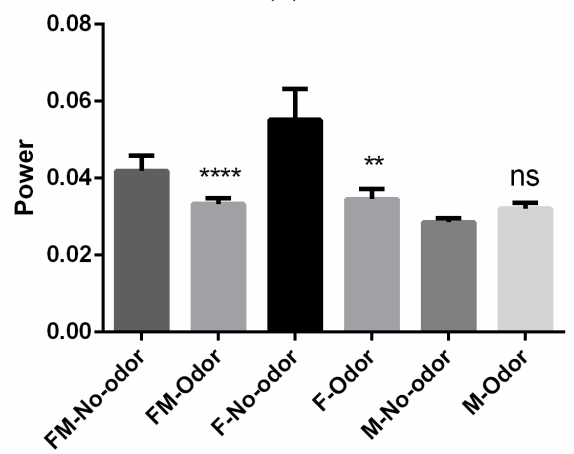

(c)

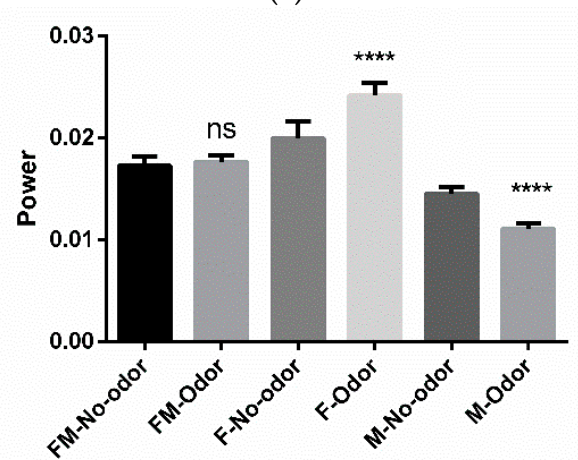

(e)

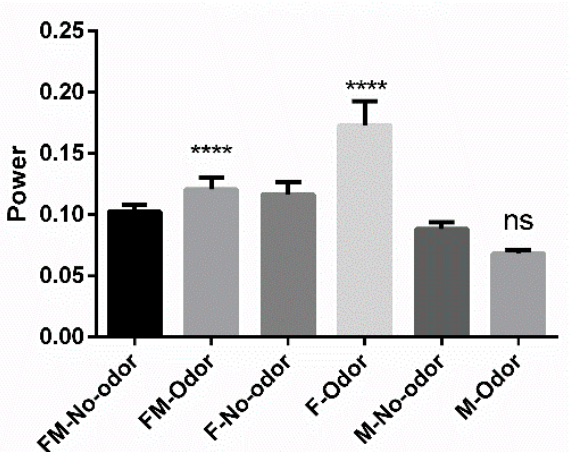

(b)

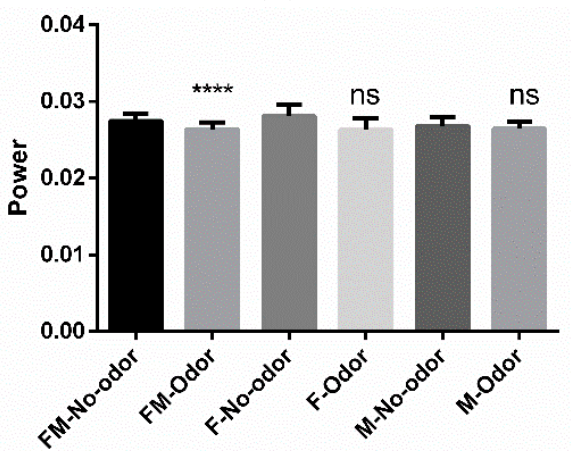

(d)

Figure 1. Power spectral analysis of human brainwave characterized by frequencies consisting of slow alpha $(9 \mathrm{~Hz})$, fast alpha $(12 \mathrm{~Hz})$, low beta $(14 \mathrm{~Hz})$, mid beta $(17 \mathrm{~Hz})$, and high beta $(25 \mathrm{~Hz})$. (a) Power spectral analysis of slow alpha brainwave in female and male subjects in absence and presence of the essential oil. (b) Power spectral analysis of fast alpha activity. (c-e) Power spectral analysis of low, mid, and high beta activities. F, M, and FM represent female subjects, male subjects, and female and male subjects, respectively. ns, ${ }^{* *}, * *$, and ${ }^{* * *}$ represent no statistical differences, $p<0.01, p<0.001$, and $p<0.0001$, respectively. 


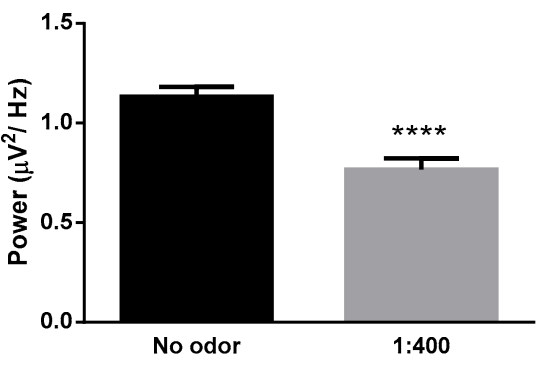

(a)

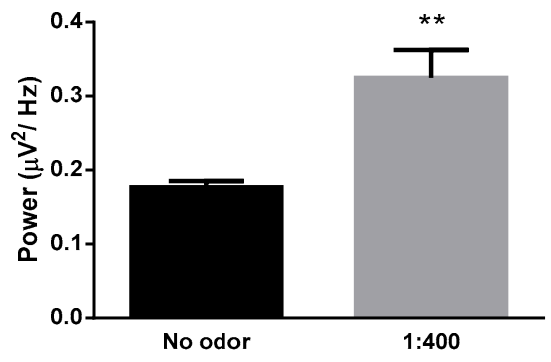

(b)

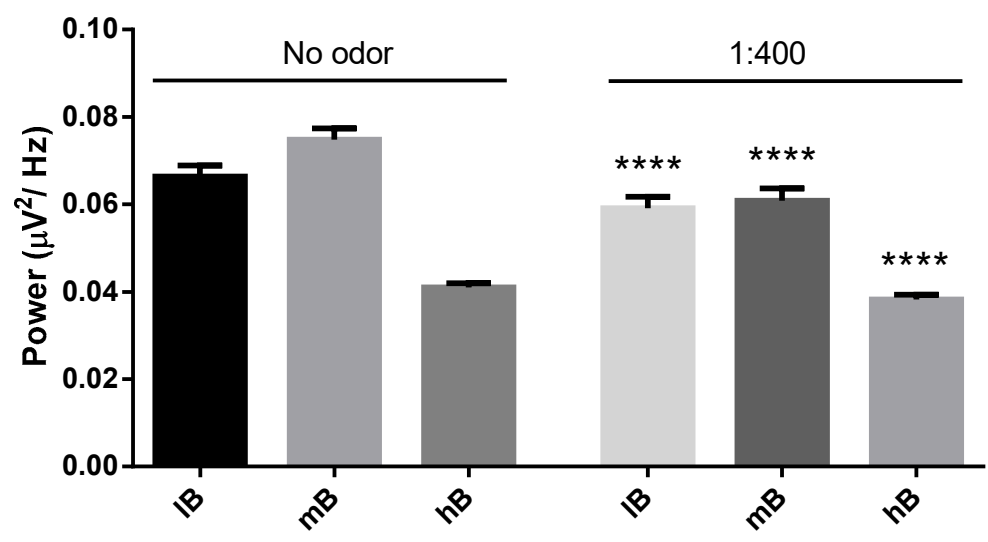

(c)

Figure 2. Power spectral analysis of human brainwave during linalool inhalation characterized by frequencies consisting of slow alpha, fast alpha, low beta, mid beta, and high beta in female subjects. (a) Slow alpha wave activities during 1:400 diluted linalool inhalation compared with absence of the odor. (b) Fast alpha wave activities during absence and presence of the odor. (c) Low, mid, and high beta wave activities during presence and absence of the odor. $\mathrm{B}, \mathrm{mB}$, and $\mathrm{hB}$ represent low beta, mid beta, and high beta, respectively. ${ }^{* *}$ and ${ }^{* * * *}$ represent $p<0.01$ and $p<0.0001$, respectively.

\subsection{Brain Area Analysis}

In this study, 32 recording electrodes were grouped into four areas of the responsible cortices underneath the scalp: the frontal, centro-temporal, parietal, and occipital areas. FP1, FP2, AF3, AF4, F7, F3, FZ, F4, F8, FC5, FC1, FC2, and FC6 were analyzed as frontal electrodes. T7, C3, CZ, C4, T8, CP5, CP1, CP2, and CP6 were analyzed as centro-temporal electrodes. P7, P3, PZ, P4, and P8 were analyzed as parietal electrodes. PO7, PO3, OZ, PO4, and PO8 were analyzed as occipital electrodes. Most of the michelia oil inhalation did not alter alpha and beta activities at parietal and occipital cortex areas (data not shown). The michelia oil inhalation affected mostly the frontal and centro-temporal brain areas. The michelia oil inhalation clearly decreased slow alpha wave activity in frontal and centro-temporal brain areas (Figure 3). Fast alpha activity was dominant in female subjects in both frontal and centro-temporal electrodes. For beta wave activities, the michelia oil inhalation reduced fast beta power at the frontal-electrode area in female participants (Figure 4). The michelia oil decreased the mid beta wave power at the centro-temporal electrode and increased the high beta wave power at frontal and centro-temporal electrodes. It showed clearly differences in both genders, which tended to reduce cerebral arousal levels in terms of beta wave reductions. It showed virtually no effects in beta wave band in male participants, who had only reduced high beta wave power in centro-temporal area electrodes. 


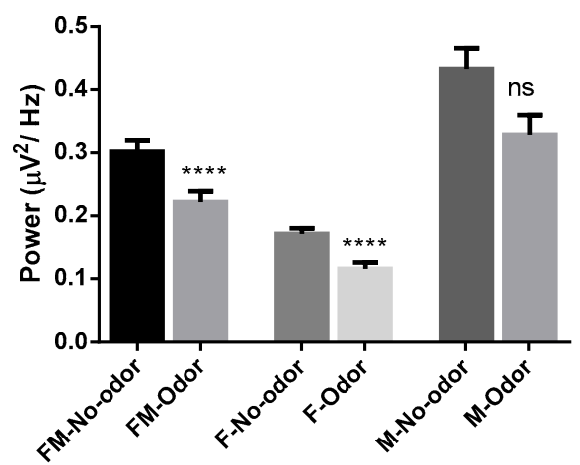

(a)

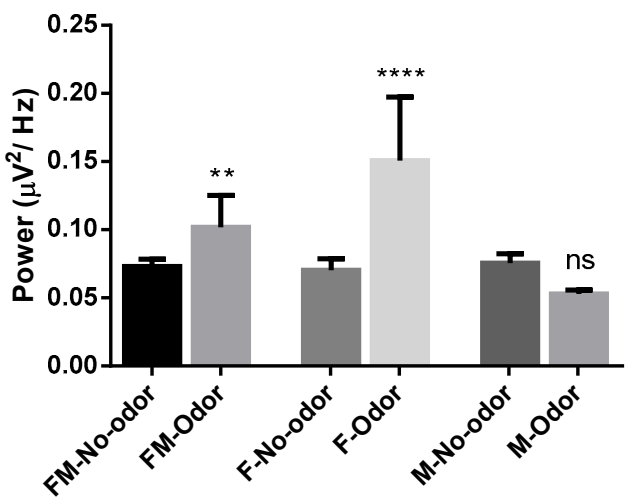

(c)

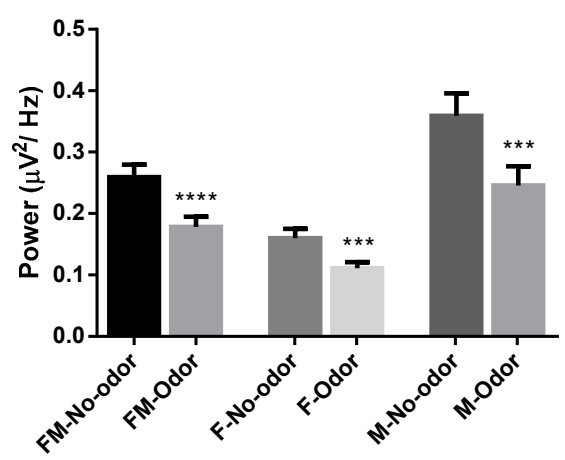

(b)

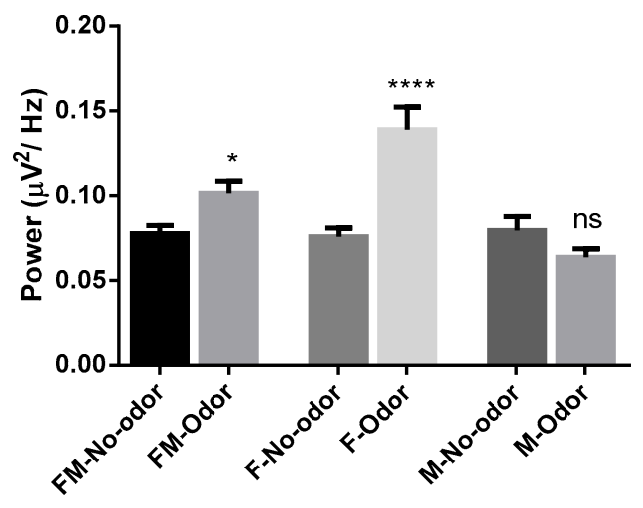

(d)

Figure 3. Brain area analysis of alpha wave activities of frontal and centro-temporal regions. (a,b) Slow alpha wave activities at frontal and centro-temporal regions, respectively. (c,d) Fast alpha wave activities at frontal and centro-temporal regions, respectively.; F, M, and FM represent female subjects, male subjects, and female and male subjects, respectively. ns, ${ }^{*}, * * * *$, and ${ }^{* * * *}$ represent no statistical differences, $p<0.05, p<0.01, p<0.001$, and $p<0.0001$, respectively.

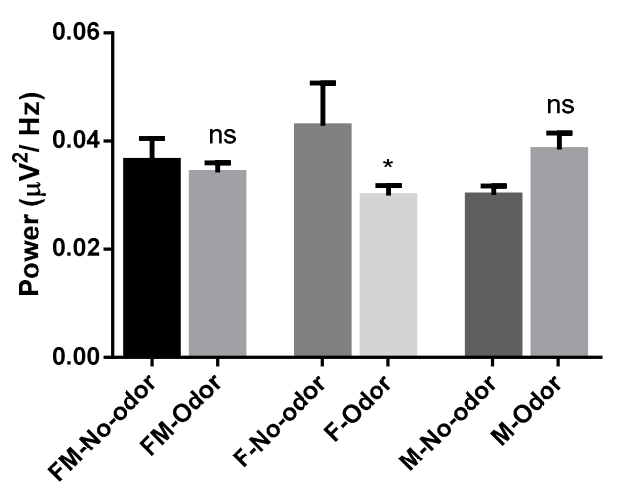

(a)

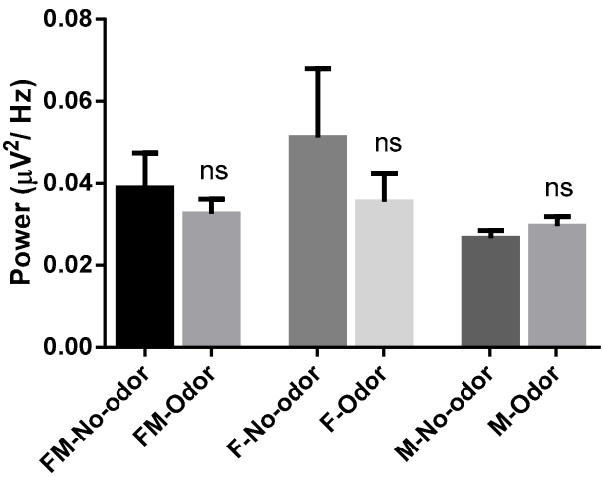

(b)

Figure 4. Cont. 


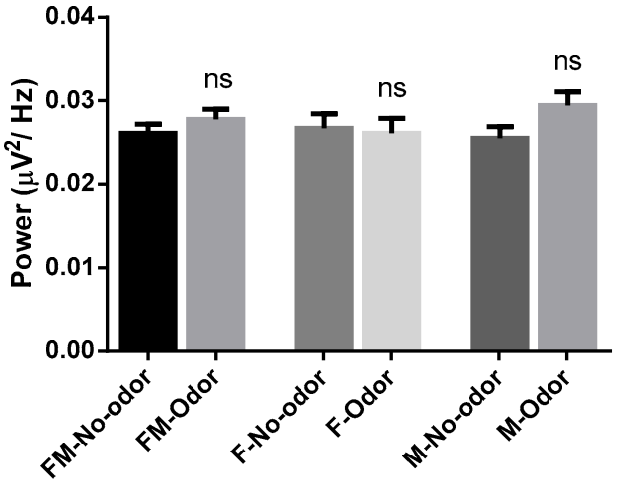

(c)

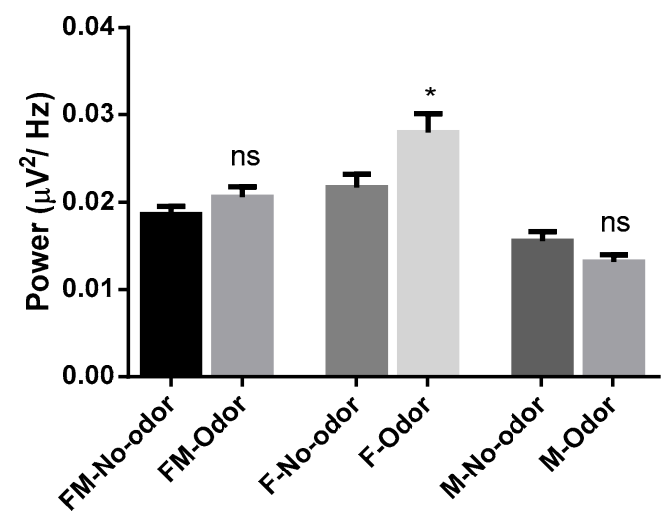

(e)

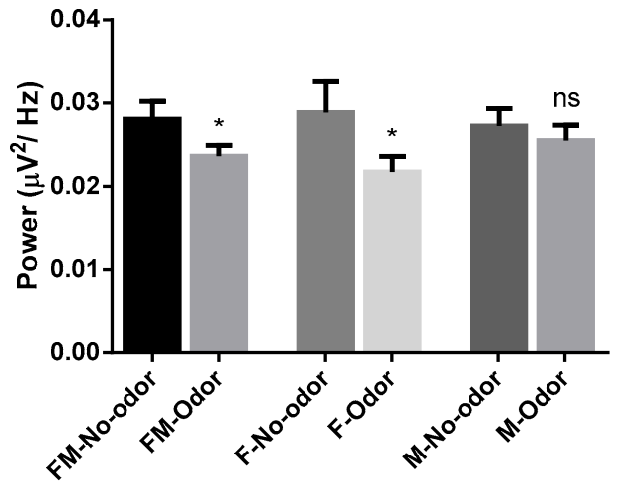

(d)

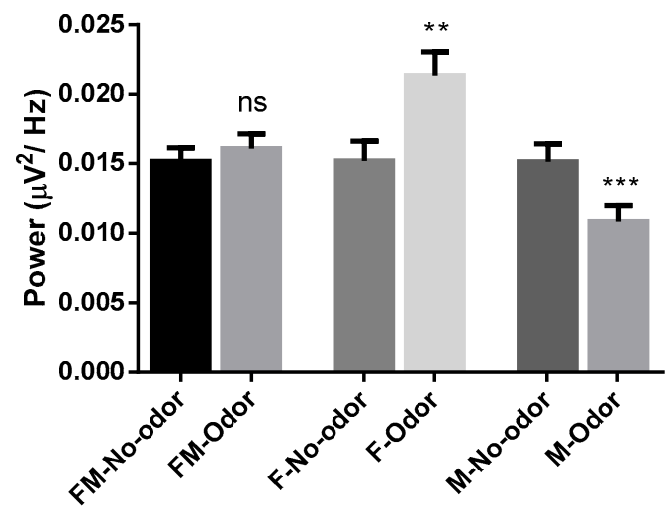

(f)

Figure 4. Brain area analysis of beta wave activities of frontal and centro-temporal regions. $(\mathbf{a}, \mathbf{b})$ Low beta wave activities at frontal and centro-temporal regions, respectively. (c-d) Mid beta wave activities at frontal and centro-temporal regions, respectively. (e-f) High beta wave activities at frontal and centro-temporal regions, respectively. F, M, and FM represent female subjects, male subjects, and female and male subjects, respectively. ns, ${ }^{*}{ }^{* *}$, and ${ }^{* * *}$ represent no statistical differences, $p<0.05$, $p<0.01$, and $p<0.001$, respectively.

\subsection{Moods and Brain-State Perception}

The michelia oil inhalation tended to reduce freshness and romantic mood in women (Figure 5). All moods and emotional responses revealed subjective results, which were very dependent on their own experience. There were no statistical differences between moods. However, a frequency shift from the most alertness beta wave power to the fast alpha wave might be a related signal, which can be further studied to precisely predict the emotional responses. 
Moods-maleVSfemale

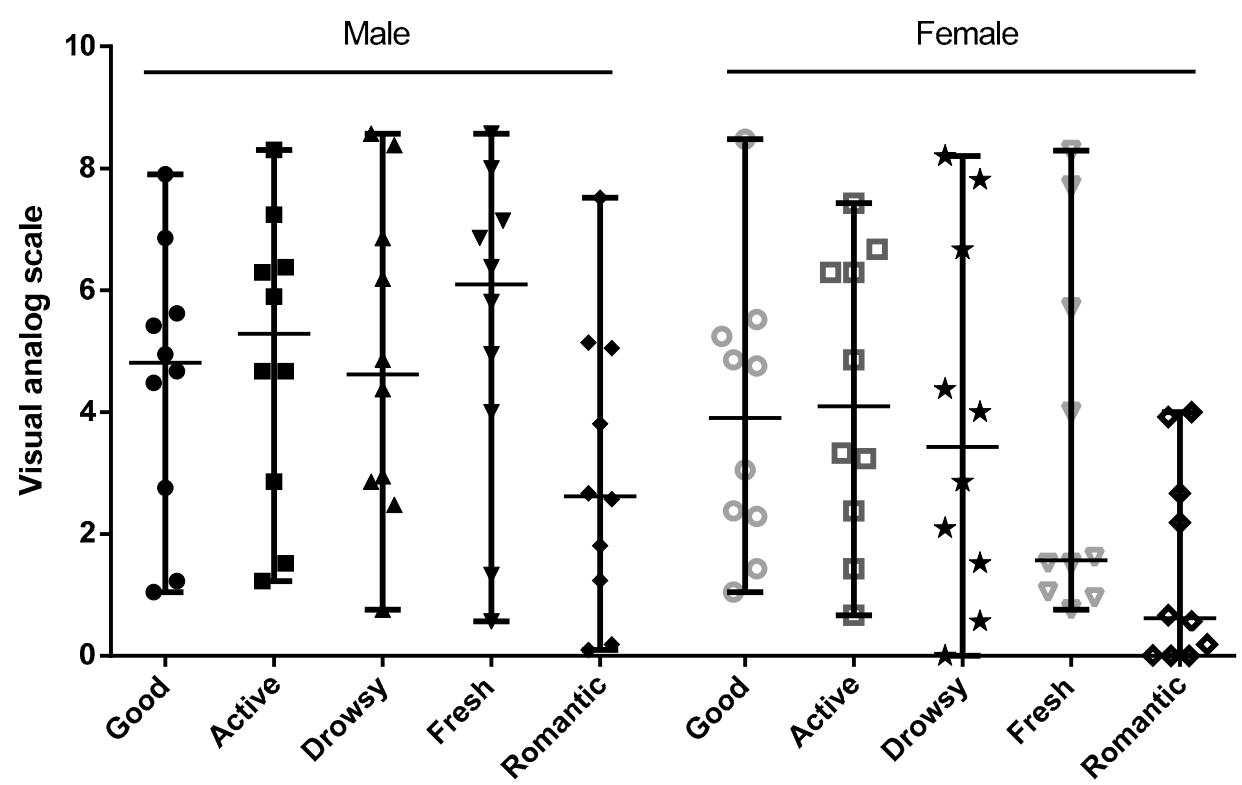

Figure 5. Moods and brain arousal states of male and female subject evaluated by a visual analog scale. Each mood and feeling were expressed in different symbols.

\section{Discussion}

Odorants can trigger responses of the nervous system via olfactory sensation, which further innervates related brain areas. Another interesting pathway is absorbed into the blood circulation through nasal and lung mucosa [8]. The olfactory system involves several brain areas, such as the limbic system, prefrontal cortex, subcortical forebrain, midbrain, and brainstem structures [19]. Each of the brain areas is responsible for their dedicated functions from basic arousal states to higher cognitive functions. In this study, we failed to detect any changes of autonomic nervous system parameters (blood pressure, heart rate, respiratory rates, and skin temperature). Only the alterations of brainwaves were detected. Alterations of brainwaves are related with brain functions. Brainwaves, such as delta wave, theta wave, alpha wave, beta wave, and gamma wave, were characterized by frequency. Delta wave is found during non-rapid eye movement sleep. Theta wave appears during drowsiness and light sleep. Alpha wave is observed during cognitive performance, mental coordination, calmness, and alertness. Beta wave is found during alertness. It is also engaged in problem solving, decision making, and focused mental activity [7]. In this study, we focus on alpha and beta wave activities, which are important brain oscillations found during the awake state. We found that the michelia oil inhalation reduced beta wave activities and slow alpha wave activity. The michelia oil inhalation increased fast alpha wave frequency concomitant with linalool inhalation. The michelia oil inhalation shows sedative effects on the brain because of beta wave band reduction. The reduction of beta and slow alpha waves is correlated with a comfortable state of the subjects [12]. A high level of alpha waves, absolute alpha, is related with a stress reduction state. Several studies showed the same sedative effects of different essential oil inhalations. Lavender, jasmine, and cannabis essential oils can also decrease beta waves $[10,12,14,20]$. Linalool is an important component which is found in this group of essential oils [7]. The underlying mechanism of arousal state alteration is still unclear. However, there is evidence that supports the theory that each inhaled essential oil is presented in the blood stream. The structure of essential oil components is readily permeable through the blood-brain barrier [21]. Several essential oil components can also action through postsynaptic transmission. Gamma-aminobutyric acid-mediated neuronal inhibition is one of the mechanisms 
underlying this sedative effect [22]. In addition, an inhibition of potassium-stimulated glutamate release and antagonism of N-methyl-D-aspartate receptors are also the action of linalool on cortical synapses [23].

In addition to pharmacological actions of essential oil molecules, thalamo-cortical and brainstem-cortical cholinergic pathways need to be attended for a detailed explanation of alertness and arousal. Cortical spectra recorded from an EEG study basically explained the wakefulness and arousal state of the brain, which is important for cognitive processes [24]. However, there is no direct evidence proving mechanisms of essential oil inhalation on arousal states. The cholinergic system may be one possible mechanism related with a slowing of the EEG as observed in Alzheimer's disease patients. More synchronization of the brainwave after essential oil inhalation still needs to be further investigated. With the advancement of computational techniques, the reduction of thalamo-cortical activity may be observed. An understanding on an alertness or arousal brain state will be an important mechanism, controlling other cognitive performance and essential oil inhalation, which will be an interesting intervention to improve cognitive performance and alternative medicine in the near future [25].

\section{Conclusions}

Michelia oil has sedative effects on human brain responses by the reduction of slow alpha, low beta, and mid beta activities. Fast alpha activity was clearly increased after oil inhalation. Linalool may be the main component, which contributes to the same patterns in the michelia oil inhalation. The action patterns may be suitable for sleep induction and relaxation oils in aromatherapy.

Author Contributions: Conceptualization, funding acquisition, writing - original draft preparation, methodology and investigation, and formal analysis, P.K.; funding acquisition and writing-original draft preparation, A.S.; methodology and investigation, S.C., J.S., and S.S.; resources and writing-review and editing, S.P., P.N.-e., and C.P.; resources and investigation, N.M. All authors have read and agreed to the published version of the manuscript.

Funding: This research was funded by the Institute of Research and Innovation, Walailak University, grant number WU_IRG61_26 and was partially supported by the new strategic research (P2P) project, Walailak University, Thailand.

Acknowledgments: We acknowledge the Research Institute for Health Sciences, Walailak University, for their laboratory supports. In this study, GC-MS analysis of Michelia alba was done by Kitiya Suhem, Walailak University.

Conflicts of Interest: The authors declare no conflict of interest.

\section{References}

1. Esposito, E.R.; Bystrek, M.V.; Klein, J.S. An elective course in aromatherapy science. Am. J. Pharm. Educ. 2014, 78, 79. [CrossRef] [PubMed]

2. Aleksic, V.; Knezevic, P. Antimicrobial and antioxidative activity of extracts and essential oils of Myrtus communis L. Microbiol. Res. 2014, 169, 240-254. [CrossRef] [PubMed]

3. Amorati, R.; Foti, M.C.; Valgimigli, L. Antioxidant Activity of Essential Oils. J. Agric. Food Chem. 2013, 61, 10835-10847. [CrossRef] [PubMed]

4. Gautam, N.; Mantha, A.K.; Mittal, S. Essential Oils and Their Constituents as Anticancer Agents: A Mechanistic View. BioMed Res. Int. 2014, 2014, 23. [CrossRef] [PubMed]

5. Pérez, G.S.; Zavala, S.M.; Arias, G.L.; Ramos, L.M. Anti-inflammatory Activity of Some Essential Oils. J. Essent. Res. 2011, 23, 38-44. [CrossRef]

6. Saad, N.Y.; Muller, C.D.; Lobstein, A. Major bioactivities and mechanism of action of essential oils and their components. Flavour Frag. J. 2013, 28, 269-279. [CrossRef]

7. Sowndhararajan, K.; Kim, S. Influence of Fragrances on Human Psychophysiological Activity: With Special Reference to Human Electroencephalographic Response. Sci. Pharm. 2016, 84, 724-751. [CrossRef]

8. Moss, M.; Oliver, L. Plasma 1,8-cineole correlates with cognitive performance following exposure to rosemary essential oil aroma. Ther. Adv. Psychopharmacol. 2012, 2, 103-113. [CrossRef]

9. Suhem, K.; Matan, N.; Matan, N.; Danworaphong, S.; Aewsiri, T. Enhanced antifungal activity of michelia oil on the surface of bamboo paper packaging boxes using helium-neon ( $\mathrm{HeNe}$ ) laser and its application to brown rice snack bar. Food Control. 2017, 73, 939-945. [CrossRef] 
10. Sugawara, Y.; Hara, C.; Tamura, K.; Fujii, T.; Nakamura, K.-i.; Masujima, T.; Aoki, T. Sedative effect on humans of inhalation of essential oil of linalool:: Sensory evaluation and physiological measurements using optically active linalools. Anal. Chim. Acta 1998, 365, 293-299. [CrossRef]

11. Kuroda, K.; Inoue, N.; Ito, Y.; Kubota, K.; Sugimoto, A.; Kakuda, T.; Fushiki, T. Sedative effects of the jasmine tea odor and (R)-(-)-linalool, one of its major odor components, on autonomic nerve activity and mood states. Eur. J. Appl. Physiol. 2005, 95, 107-114. [CrossRef] [PubMed]

12. Masago, R.; Matsuda, T.; Kikuchi, Y.; Miyazaki, Y.; Iwanaga, K.; Harada, H.; Katsuura, T. Effects of Inhalation of Essential Oils on EEG Activity and Sensory Evaluation. J. Physiol. Anthropol. Appl. Hum. Sci. 2000, 19, 35-42. [CrossRef] [PubMed]

13. Sayowan, W.; Siripornpanich, V.; Hongratanaworakit, T.; Kotchabhakdi, N.; Ruangrungsi, N. The effects of jasmine oil inhalation on brain wave activities and emotions. J. Health Res. 2013, 27, 73-77.

14. Gulluni, N.; Re, T.; Loiacono, I.; Lanzo, G.; Gori, L.; Macchi, C.; Epifani, F.; Bragazzi, N.; Firenzuoli, F. Cannabis Essential Oil: A Preliminary Study for the Evaluation of the Brain Effects. Evid.-Based Compl. Altern. 2018, 2018, 11. [CrossRef]

15. Ha, C.T.T.; Thai, T.H.; Diep, L.N.; Thanh, T.X.; Thu Thuy, D.T.; Tra, N.T.; Thu Ha, N.T. Chemical composition and antimicrobial activity of the essential oils from stems and leaves of Michelia alba D. C. growing in Vietnam. TAP CHI SINH HOC 2018, 2018, 40.

16. Songsamoe, S.; Matan, N.; Matan, N. Antifungal activity of Michelia alba oil in the vapor phase and the synergistic effect of major essential oil components against Aspergillus flavus on brown rice. Food Control. 2017, 77, 150-157. [CrossRef]

17. Leelapornpisid, P.; Chansakaow, S.; Chaiyasut, C.; Wongwattananukul, N. Antioxidant Activity of Some Volatile Oils and Absolutes from Thai Aromatic Plants; International Society for Horticultural Science (ISHS): Leuven, Belgium, 2008; pp. 61-66.

18. Sowndhararajan, K.; Cho, H.; Yu, B.; Song, J.; Kim, S. Effect of inhalation of essential oil from Inula helenium L. root on electroencephalographic (EEG) activity of the human brain. Eur. J. Integr. Med. 2016, 8, $453-457$. [CrossRef]

19. Shipley, M.T.; Murphy, A.Z.; Rizvi, T.A.; Ennis, M.; Behbehani, M.M. Chapter 22 Olfaction and brainstem circuits of reproductive behavior in the rat. In Progress in Brain Research; Holstege, G., Bandler, R., Saper, C.B., Eds.; Elsevier: Amsterdam, The Netherlands, 1996; Volume 107, pp. 355-377.

20. Klemm, W.R.; Lutes, S.D.; Hendrix, D.V.; Warrenburg, S. Topographical EEG maps of human responses to odors. Chem. Senses 1992, 17, 347-361. [CrossRef]

21. Boyle, R.R.; McLean, S.; Brandon, S.; Wiggins, N. Rapid Absorption of Dietary 1,8-Cineole Results in Critical Blood Concentration of Cineole and Immediate Cessation of Eating in the Common Brushtail Possum (Trichosurus vulpecula). J. Chem. Ecol. 2005, 31, 2775-2790. [CrossRef]

22. Brum, L.F.; Elisabetsky, E.; Souza, D. Effects of linalool on [(3)H]MK801 and [(3)H] muscimol binding in mouse cortical membranes. Phytother. Res. 2001, 15, 422-425. [CrossRef]

23. Silva Brum, L.F.; Emanuelli, T.; Souza, D.O.; Elisabetsky, E. Effects of linalool on glutamate release and uptake in mouse cortical synaptosomes. Neurochem. Res. 2001, 26, 191-194. [CrossRef] [PubMed]

24. Platt, B.; Riedel, G. The cholinergic system, EEG and sleep. Behav. Brain Res. 2011, 221, 499-504. [CrossRef] [PubMed]

25. Jensen, O.; Mazaheri, A. Shaping functional architecture by oscillatory alpha activity: Gating by inhibition. Front. Hum. Neurosci. 2010, 4, 186. [CrossRef] [PubMed]

(C) 2020 by the authors. Licensee MDPI, Basel, Switzerland. This article is an open access article distributed under the terms and conditions of the Creative Commons Attribution (CC BY) license (http://creativecommons.org/licenses/by/4.0/). 